\title{
Ciprofloxacin in Respiratory Tract Infections
}

Faroque A. Khan, M.B.

East Meadow, New York

DOI: http://dx.doi.org/10.5915/23-1-14377

\begin{abstract}
Of the quinolone class of antimicrobials, only oral ciprofloxacin is currently approved for respiratory indications. Ciprofloxacin has good tissue penetration and is active against most gram-negative and gram-positive pathogens, including Staplylococcus sp. It is, however, less effective against anaerobic bacteria and Streptococcus pneumoniae. The drug may be useful for managing bacterial exacerbations of COPD and for treating elderly patients with respiratory tract infections, including nosocomial pneumonias. Ciprofloxacin probably alters metabolism of theophylline and some antacids interfere with its absorption and antibacterial activity.
\end{abstract}

Key words: Quinolone, ciprofloxacin, respiratory tract infection.

The fluorinated quinolones represent a promising new class of antimicrobial agents with a broad range of activity against both gram-negative and grampositive organisms. The first of the quinolones, nalidixic acid, was developed in the 1960 s. This agent was adequate for treatment of urinary tract infections caused by some gram-negative organisms, but did not have sufficient tissue penetration after oral dosing to be of use in systemic infections. The rather rapid development of resistant bacteria and superinfection with resistant organisms, such as Psuedomonas aeroginosa, posed additional problems with its use.

The newer quinolones - norfloxacin, pefloxacin, enoxacin, ofloxacin, and ciprofloxacin - have excellent tissue penetration after oral ingestion. Tissue concentrations are well above the minimal inhibitory concentrations (MICs) for most gram-negative and gram-positive pathogens that may be encountered in

From the Department of Medicine

Nassau County Medical Center

East Meadow, NY

Presented at the IMA 22nd Annual Convention

Orlando, Florida, July 1989.

Reprint Requests: Faroque A. Khan, M.B.

Chairman, Department of Medicine

Nassau County Medical Center

2201 Hempstead Turnpike

East Meadow, NY 11554 clinical practice.

Ciprofloxacin is presently the only fluoroquinolone approved by the Food and Drug Administration for respiratory indications. It is active against many common pathogens of the respiratory tract, including Hemophilus influenzae, Streptococcus pneumoniae, Branhamella catarrhalis, and P. aeruginosa. About $90 \%$ of Pseudomonas strains are inhibited by a dose of less than $1 \mathrm{mcg} / \mathrm{mL}$ of ciprpofloxacin. Some activity against Legionella and mycobacteria organisms has also been demonstrated. ${ }^{1}$ Ciprofloxacin has been shown to be effective against beta-lactamase-producing organisms and methicillin-resistant Staphylococcus aureus.'

This article reviews the current applications of ciprofloxacin in the treatment of respiratory tract infections - particularly, bacterial bronchitis and pneumonia. This review is based on reports in the literature and on the author's personal experience in using ciprofloxacin to manage various types of respiratory infections in more than 500 adult patients. ${ }^{2-4}$

The article by Longworth and Ahmad' review the etiology of community-acquired respiratory infections and describes the current approach to the treatment of those infections. Chaudhary ${ }^{6}$ has outlined the diagnostic approach usually undertaken in attempting to arrive at an etiologic diagnosis of respiratory infections. The problems associated with the interpretation, false-positive and false-negative results of sputum gram stain and culture are to be 
Table 1. Sensitivity of common respiratory tract pathogens to ciprofloxacin.

SENSITIVE $(\mathrm{MIC}<1 \mathrm{mcg} / \mathrm{mL})$

Branhamella catarrhalis

Hemophilus influenzae

Klebsiella sp.

Neisseria sp.

Pseudomonas aeruginosa

Serratia marcescens

Stamphylococcus aureus

INTERMEDIATE (MIC 1 to $2 \mathrm{mcg} / \mathrm{mL}$ )

Mycobacterium tuberculosis

Legionella sp.

Streptococcus pneumoniae and other

Streptococcus sp.

Resistant (MIC $>2 \mathrm{mcg} / \mathrm{mL}$ )

Anaerobic cocci

Bacteroides sp.

Pseudomonas maltophilia

Pseudomonas cepacia

\section{INSUFFICIENE DATA}

Chlamydia sp.

Mycoplasma sp.

Note: Inoculum size not a factor.

noted in particular.

\section{Ciprofloxacin - In vitro activity}

Preclinical in vitro studies have shown ciprofloxacin to be active against more than 6,000 strains of bacterial pathogens, including those that are most frequently implicated in respiratory infections. MICs of ciprofloxacin are generally less than $1 \mathrm{mcg} / \mathrm{mL}$ for B. catarrhalis, H. influenzae, Klebsiella sp., Neisseria sp., P. aeruginosa, Ser. marcescens, and Staph. aureus (Table 1).

Ciprofloxacin has been shown to be moderately active against mycobacteria, particularly Mycobacterium tuberculosis. Sanders and coworkers $^{1}$ found that six to 12 strains of $\mathrm{M}$. tuberculosis tested were inhibited by $1.6 \mathrm{mcg} / \mathrm{mL}$ or less of ciprofloxacin. Activity against Legionella organisms, ${ }^{7}$ as well as Strep. pneumoniae and other Streptococcus sp. ${ }^{2,4}$ have also been reported.

Table 2 is a summary of ciprofloxacin MIC ranges for common respiratory tract pathogens. ${ }^{2-4}$

\section{Pharmacokinetics}

Quinolones are rapidly absorbed from the gastrointestinal tract and slowly eliminated from serum. The elimination half-time ranges from three to five hours. The mean systemic bioavailability of ciprofloxacin is about $85 \%$. A high volume of distribution suggests efficient diffusion into the ex- travascular space and good tissue penetration.

The tissue penetration characteristics of ciprofloxacin are strikingly superior to those of most other groups of antimicrobial agents after oral or intravenous administration. In many tissues, the concentration of ciprofloxacin has been observed to be higher than the serum concentration at corresponding times after dosing." Therapeutic concentrations after oral administration have been attained in difficult-to-penetrate tissue, such as bone, prostate, and lung. In fact, studies have shown that ciprofloxacin may concentrate in lung tissue at levels three to nine times the serum concentration. ${ }^{9}$

Although the significance of antibiotic levels in bronchial secretions and pleural fluid is controversial, it is widely believed that high drug concentrations may be associated with higher cure rates in patients with lower respiratory tract or pleural infections.

Bergogne-Berezin and colleagues ${ }^{8}$ assessed the penetration of ciprofloxacin into bronchial secretions in 21 patients who were given a single oral dose of $500 \mathrm{mg}$. Afterward, ten successive sputum samples were collected over a 12-hour period. Peak serum levels of 2.2 to $1.3 \mathrm{mcg} / \mathrm{mL}$ were obtained two hours post dose. These levels decreased slowly to 0.6 to 0.4 $\mathrm{mcg} / \mathrm{mL}$ at six hours post dose. The concentration in bronchial tissue reached $0.5 \mathrm{mcg} / \mathrm{mL}$ after two hours and remained stable for six hours, with a range of 0.5 to $0.8 \mathrm{mcg} / \mathrm{mL}$. This level was well above the MIC for most pathogens that cause respiratory infections. The ratio of bronchial to serum levels was 0.19 at two hours, and 0.95 at six hours.

In another study, Bergogne-Berezin' reported on the penetration of ciprofloxacin into lung parenchymal tissue. Following a preoperative infusion of $100 \mathrm{mg}$ of ciprofloxacin, surgical samples of the lung were obtained. The lung tissue level exceeded the corresponding serum level by $300 \%$ to $900 \%$. Ciprofloxacin also achieved a high concentration in the pleural fluid, with a peak pleural level obtained six to nine hours after administration. Twenty-four hours after administration, the concentration of ciprofloxacin in the pleural fluid averaged $0.9 \mathrm{mcg} / \mathrm{mL}$.

Reid et al $^{10}$ have also demonstrated very high ciprofloxacin concentration in the bronchial mucosa after a single oral or parenteral dose yielding tissue concentrations in excess of the $90 \%$ minimum inhibitory concentration value of the common respiratory pathogen including $\mathrm{S}$. pneumoniae.

Marlin and co-workers ${ }^{11}$ studied the distribution ratio of the quinolone enoxacin $(400 \mathrm{mg})$ between plasma and bronchial mucosa in patients after distribution equilibrium was established. They also compared the absolute bronchial mucosal concentration achieved with the in vitro bacterial activity of enoxacin. The authors concluded that equilibrium between bronchial mucosa and plasma is achieved 
Table 2. Antibacterial activity of ciprofloxacin against common respiratory tract pathogens.

\begin{tabular}{llll}
\hline \multicolumn{1}{c}{ Organism } & $\begin{array}{c}\text { MIC range } \\
(\mathbf{m c g} / \mathbf{m L})\end{array}$ & $\begin{array}{c}\text { MIC-50 } \\
(\mathbf{m c g} / \mathbf{m L})\end{array}$ & $\begin{array}{c}\text { MIC-90 } \\
(\mathbf{m c g} / \mathbf{m L})\end{array}$ \\
\hline Klebsiella pneumoniae & $0.008-0.5$ & $0.016-0.032$ & $0.03-0.25$ \\
Hemophilus influenzae & $0.004-0.16$ & $0.008-0.016$ & $0.008-0.016$ \\
Branhamella catarrhalis & $0.016-0.064$ & 0.064 & 0.06 \\
Pseudomonas aeruginosa & $0.02-4$ & $0.12-0.25$ & $0.5-1$ \\
Pseudomonas sp. & $<0.004-0.25$ & $0.004-0.128$ & $<0.004-0.25$ \\
Serratia marcescens & $0.016-1$ & $0.06-0.125$ & $0.12-0.40$ \\
Streptococcus pneumoniae & $0.2-4$ & $0.5-1$ & $2-4$ \\
Staphylococcus aureus Methicillin sensitive & $0.062-2$ & $0.25-0.5$ & $0.5-0.8$ \\
Methicillin resistant & $0.1-1$ & $0.25-0.5$ & $0.5-1$ \\
Mycobacterium tuberculosis & $0.25-4$ & $0.5-2$ & $1-4$ \\
Gram-negative anaerobic cocci & $0.25-16$ & 4 & 16 \\
Bacteroides fragilis & $0.25-32$ & $2-4$ & $4-16$ \\
\hline
\end{tabular}

within three hours of dosing. The mean bronchial mucosal concentration of enoxacin was 117.0 (47.8 $\mathrm{mcg} / \mathrm{g})$, the mean plasma concentration was $3.1(1.1$ $\mathrm{mcg} / \mathrm{ml}$ ), and the mean ration was 46.8 . These data suggest the possibility of active transport of quinolones into the bronchial mucosa. Avid binding to tissue macromolecules may account for the extensive accumulation of enoxacin in the bronchial respiratory tract.

\section{Drug Interactions}

Drug-related alterations of theophylline metabolism are a well-known phenomenon. Erythromycin, cimetidine, and propranolol are among the drugs known to inhibit theophylline clearance, while phenobarbital, phenytoin, and isoproterenol may increase theophylline clearance.

During one of our early trials of ciprofloxacin, we observed that some patients exhibited signs and symptoms suggesting theophylline toxicity. Furthermore, since it had been shown recently that enoxacin could inhibit the clearance of theophylline, ${ }^{12}$ we decided to assess the effects of ciprofloxacin on theophylline in 33 patients taking both drugs. ${ }^{13}$

Sixteen of the patients had asthma and 17 had chronic obstructive pulmonary disease (COPD). All were receiving theophylline therapy as outpatients. Theophylline was administered intravenously in standard titrated doses to patients receiving $750 \mathrm{mg}$ of oral ciprofloxacin twice daily. In 20 patients $(61 \%)$ - including 13 out of 15 patients over the age of 60 - serum theophylline levels incresed by $4 \mathrm{mcg} / \mathrm{mL}$ or more. In the other 13 patients $(39 \%)$, no increase in theophylline levels was observed.

Our results suggest that increases in serum theophylline levels are more likely to occur in patients older than 60 years. Fourteen of seventeen patients with COPD had increases in serum theophylline levels, and eleven of these patients were 60 years of age or older. Thus, given the increased incidence of COPD in older patients, COPD itself is probably not as great a risk factor as age. In any case, when a patient is receiving concomitant ciprofloxacin and theophylline therapy, it is important to monitor theophylline levels and to watch for the symptoms of theophylline toxicity.

There has been some concern over the effects of antacids on the serum levels and antibacterial activity of fluorinated quinolones. Concomitant adminisration of antacids containing aluminum or magnesium with $500 \mathrm{mg}$ of ciprofloxacin results in a sixfold to tenfold decrease in peak serum levels of the antibiotic. ${ }^{14}$ Antacid preparations that include aluminum or magnesium interfere with absorption of the antibiotic and reduce the antibacterial activity of the drug; therefore, they should not be used during therapy with any fluorinated quinolone. Antacids containing calcium, however, apparently have no ef- 
fect on blood ciprofloxacin levels. The interaction between ciprofloxacin and cyclosporine, warfarim, rifampin, non-steroidal anti-inflammatory agents, although mentioned in the literature, have not been fully established. ${ }^{14}$

\section{Clinical efficacy}

Based on analysis of many clinical trials, it is evident that ciprofloxacin is effective in managing bacterial respiratory tract infections in a number of situations. ${ }^{15-21}$

Gleadhill and colleagues's compared oral ciprofloxacin and amoxicillin for efficacy and safety in 48 patients. Patients were randomly assigned to receive standard doses of either drug over ten days. Twenty-six received ciprofloxacin ( $500 \mathrm{mg}$ twice daily); 22 received amoxicillin $(250 \mathrm{mg}$ three times daily). Equally successful outcomes were achieved with ciprofloxacin $(81 \%)$ and amoxicillin $(82 \%)$. Both regimens were safe and produced few, if any, adverse effects. A specific bacterial cause was determined in about half the cases. Among these, eradication rates were higher for ciprofloxacin $(87 \%)$ than for amoxicillin (64\%). Amoxicillin was effective against B. catarrhalis infections.

Kobayashi ${ }^{16}$ reported on a large, multicenter, open trial involving 571 patients in Japan. Seventy percent of the patients received $600 \mathrm{mg}$ of oral ciprofloxacin daily. Dosages ranged from 200 to $1,200 \mathrm{mg} / \mathrm{d}$. Clinical efficacy was evaluated in 542 patients; safety, in 568. Efficacy was "excellent to good" in $81 \%$ of patients with pneumonia and in $71 \%$ of patients with chronic bronchial infections. The overall bacteriologic eradication rate was $68 \%$. Against $\mathrm{H}$. influenzae, the rate was $91 \%$. While none were serious, side effects occurred in $4.6 \%$ of patients.

We have recently completed a prospective trial, comparing intravenous and oral ciprofloxacin with intravenous ceftazidime, in 122 hospitalized adult patients with lower respiratory tract infections. ${ }^{4}$ Of these patients, 111 had radiographic evidence of pneumonia; the remaining 11 had acute purulent bronchitis. Ciprofloxacin was as effective as ceftazidime and produced a $91 \%$ clinical cure rate. Significantly more pretreatment bacterial isolates were susceptible to ciprofloxacin. The drug also had a significantly higher rate of bacterial eradication in sputum than did ceftazidime. Ciprofloxacin showed broad in vitro antibacterial activity, with particularly low MICs for gram-negative organisms. The drug was well tolerated, producing few adverse effects. It was also less expensive; treatment of patients in the ceftazidime group cost an additional \$4,144 (\$74 per patient).

We compared the safety and efficacy of oral ciprofloxacin (750 mg twice daily) with that of ampicillin (500 $\mathrm{mg}$ four times daily) in a double-blind, prospective clinical trial in patients with bacterial bronchitis. ${ }^{2}$ Of the 87 patients enrolled in the study, 42 were randomized to ciprofloxacin and 45 to ampicillin. The patients ranged in age from 23 to 83 years, with a mean age of 53.3 years. Excellent clinical results were achieved in both groups. Clinical cure, defined as the disappearance of previously documented signs and symptoms of infection, was obtained in $41(98 \%)$ of the 42 patients treated with ciprofloxacin and in $40(89 \%)$ of 45 of those who were given ampicillin. This difference in outcome was not statistically significant.

In our clinical experience, the gram-negative bacteria most commonly identified during exacerbations of COPD are Hemophilus, Pseudomonas, and Klebsiella. Our study disclosed that these organisms, as well as other gram-negative organisms tested, were highly susceptible to ciprofloxacin (P less than .05) MICs for all were less than $0.125 \mathrm{mcg} / \mathrm{ml}^{2}$ While 26 of 115 bacterial isolates were resistant to ampicillin, as shown by disk diffusion susceptibility testing, none was resistant to ciprofloxacin.

Ciprofloxacin achieved significantly better sputum sterilization than did ampicillin ( $\mathrm{P}$ less than .05). Forty $(95 \%)$ of 42 patients who received ciprofloxacin had sterile sputum cultures at the close of therapy, compared with $30(75 \%)$ of the 40 patients who completed ampicillin therapy.

Clinical cure was not achieved with ciprofloxacin in one patient, a 75-year-old man who, in addition to bacterial bronchitis, had COPD and diabetes. Since the isolated pathogen, $\mathrm{P}$. aeruginosa, was susceptible to ciprofloxacin, the persistence of clinical infection in this patient was probably attributable to advanced age and underlying medical problems.

Ciprofloxacin was well tolerated in this study. There were few adverse effects and patients had a significantly lower incidence of diarrhea than did those receiving ampicillin $(\mathrm{P}=$ less than .05$)$.

We have also conducted a trial of the safety and efficacy of oral ciprofloxacin in the treatment of $14 \mathrm{pa}$ tients with community or hospital-acquired pneumonia. ${ }^{3}$ Of these patients, 13 had underlying lung disease. The patients ranged in age from 26 to 72 years, with a mean age of 46 years. During the trial, they received $750 \mathrm{mg}$ of ciprofloxacin twice daily for an average of 11.5 days.

Clinical cure, defined as disapperance of signs and symptoms of infection, clearing of the chest film, and decrease of an elevated leukocyte count, was obtained in $12(86 \%)$ of the patients. Of these cured patients, five $(42 \%)$ showed significant roentgenographic clearing in three weeks.

One of the two patients who failed to respond to therapy had a presumed anaerobic aspiration pneumonia and a history of alcohol abuse. The other had bronchogenic carcinoma and a permanent tracheostomy. The latter patient had received multiple courses of antibiotic therapy for nosocomial in- 
Table 3. Efficacy of ciprofloxacin against Streptococcus pneumoniae respiratory tract infection.

\begin{tabular}{|c|c|c|c|c|c|c|c|}
\hline \multirow{2}{*}{ Trial } & \multirow{2}{*}{$\begin{array}{l}\text { Number } \\
\text { of } \\
\text { patients* }\end{array}$} & \multirow{2}{*}{$\begin{array}{l}\text { Number } \\
\text { of } \\
\text { isolatest }\end{array}$} & \multirow{2}{*}{$\begin{array}{c}\text { MIC } \\
\text { range } \\
\text { (ug/mL) }\end{array}$} & \multirow{2}{*}{ (Mean) } & \multicolumn{2}{|c|}{ Outcome (N) } & \multirow{2}{*}{$\begin{array}{l}\text { Ciprofloxacin } \\
\text { dosagett }\end{array}$} \\
\hline & & & & & Clinical & Bacteriologic & \\
\hline Wollschlager $^{2}$ & 7 & 8 & $.008-4.0$ & (NA) & $C(7 / 7)$ & $E(6 / 7)$ & $750 \mathrm{mg}$ \\
\hline Khan ${ }^{4}$ & 9 & 9 & $0.5-2$ & (1.1) & $\begin{array}{l}C(8 / 9) \\
F(1 / 9)\end{array}$ & $\mathrm{E}(8 / 9)$ & $\begin{array}{l}200 \mathrm{mg} \text { intravenously twice } \\
\text { a day for } 3 \text { to } 5 \text { days, } \\
\text { followed by } 500 \mathrm{mg} \text { orally } \\
\text { twice a day }\end{array}$ \\
\hline Gleadhill $^{15}$ & 7 & 12 & $0.85-3.40$ & (1.56) & $C(7 / 7)$ & $E(7 / 7)$ & $500 \mathrm{mg}$ \\
\hline Kobayashi $^{16}$ & 25 & 42 & NA & (NA) & $\begin{array}{l}C(23 / 25) \\
F(2 / 25)\end{array}$ & $\begin{array}{l}E(29 / 42) \\
P(13 / 42)\end{array}$ & $\begin{array}{l}200 \text { to } 1,200 \mathrm{mg}(70 \% \\
\text { received } 600 \mathrm{mg} \text { daily) }\end{array}$ \\
\hline \multirow[t]{2}{*}{ Davies $^{17}$} & $\begin{array}{l}11 \text { single } \\
\text { isolate }\end{array}$ & 48 & $0.25-2$ & $\begin{array}{l}(0.73 \\
\text { pretreat- } \\
\text { ment })\end{array}$ & $\mathrm{I}(9 / 26)$ & $\mathrm{P}(21 / 48)$ & 500 to $1,000 \mathrm{mg}$ \\
\hline & $\begin{array}{l}15 \text { multiple } \\
\text { isolates }\end{array}$ & & $0.25-7$ & $\begin{array}{l}(0.93 \\
\text { post- } \\
\text { treat- } \\
\text { ment })\end{array}$ & $F(17 / 26)$ & & \\
\hline Ernst $^{18}$ & 6 & 6 & NA & (NA) & $C(6 / 6)$ & (NA) & $750 \mathrm{mg}$ \\
\hline Fass $^{19}$ & 7 & 7 & $1-8$ & (NA) & $C(7 / 7)$ & $E(7 / 7)$ & $500 \mathrm{mg}$ \\
\hline Esposito $^{20}$ & 3 & 3 & $0.015-0.5$ & $(0.255)$ & $\begin{array}{l}\mathrm{C}(1 / 3) \\
\mathrm{I}(2 / 3)\end{array}$ & $\begin{array}{l}E(2 / 3) \\
P(1 / 3)\end{array}$ & $250 \mathrm{mg}$ \\
\hline $\begin{array}{l}\text { Chrysan- } \\
\text { thopoulos }\end{array}$ & 12 & 12 & $0.5-1$ & (NA) & NA & (NA) & $\begin{array}{l}200 \mathrm{mg} \text { intravenously twice } \\
\text { a day for } 2 \text { to } 10 \text { days, } \\
\text { followed by } 500 \mathrm{mg} \text { orally } \\
\text { twice a day }\end{array}$ \\
\hline
\end{tabular}

C, cured; F, failure; I, improvement; $\quad$ E, eradication, $\quad$ P, persistence; $\quad$ NA, not available.

*With Streptococcus pneumoniae infection.

†Streptococcus pneumoniae (multiple isolates of same organism in some patients).

$\dagger \dagger$ All doses given orally, twice a day, unless otherwise noted.

fections during the previous three months. Side effects of ciprofloxacin were mild and self-limited. No patient had to be withdrawn from therapy. A theophylline-related adverse reaction was suspected in one patient.

Pathogens were identified by gram stain and sputum culture in 13 of 14 patients. Seventeen isolates were obtained. Pneumococci were the most common organisms, accounting for $29 \%$ of the isolates, followed by Hemophilus sp., which accounted for $24 \%$ of isolates. Among patients with COPD or asthma, strains of Hemophilus were identified in four, and other gram-negative bacteria, in three Streptococci were identified in two.

Eradication of bacteria was attained in 11 of the 13 patients we were able to evaluate. Of the 17 isolates, $14(82 \%)$ were sensitive to ciprofloxacin and three were intermediate in sensitivity. While MICs for Strep: pneumoniae were relatively high (1.0 to 4.0 $\mathrm{mcg} / \mathrm{mL}$ ), organisms were eradicated in four of five patients, all of whom were judged to have attained clinical cure and roentgenographic clearning.

Similar results have been obtained in other clinical trials. For example, Ernst and co-workers" ${ }^{18}$ reported on the effectiveness of oral ciprofloxacin in 25 patients with pneumonia, 19 of whom had bacterial isolates in sputum or blood. Patients were treated twice a day with $750 \mathrm{mg}$ of the drug. All showed clinical improvement.

Table 3 summarizes the results of nine ciproflox- 
acin trials on patients with Strep. pneumoniae infection conducted in Europe, ${ }^{15,19-21}$ Japan, ${ }^{16}$ and the United States. ${ }^{2,4,17,18}$ Although the number of patients with Strep. pneumoniae respiratory tract infection in each study is small, the cumulative total of patients is 102 .

In analyzing the results of these studies, several observations may be made. Based on the studies that reported clinical cure rates, $59(92 \%)$ of 64 patients were cured and two showed improvement. ${ }^{20}$ There were three failures. ${ }^{4,16}$

The study by Davies and colleagues ${ }^{17}$ reported unsatisfactory results in that only nine of 26 patients improved. In the remaining 17 patients, therapy failed. Furthermore, 21 of the 48 Strep. pneumoniae isolates persisted after completion of therapy.

There appears to have been problems in the Davies study. Four different drug regimens were used and two separate lots of $750 \mathrm{mg}$ ciprofloxacin tablets were used. Interestingly, this was one of the earliest studies, and all subsequent investigations have had quite contrary results. Therefore, this particular study probably does not accurately reflect the performance of ciprofloxacin against Strep. pneumoniae respiratory tract infection.

The MICs for Strep. pneumoniae reported in these nine studies have a wide range, which is quite consistent with earlier in vitro studies done with ciprofloxacin and Strep. penumoniae. Thus, it appears that the high MICs do not interfere with the action of the drug. The explnation of the demonstrated effectiveness of ciprofloxacin against Strep. pneumoniae is found in its pharmacokinetics.

The drug's extensive penetration into the respiratory tract helps to explain the apparent paradox between the in vitro susceptibility and clinical results in the treatment of Strep. penumoniae infection. The very high lung parenchymal and bronchial tissue levels achieved with ciprofloxacin apparently overcome the marginal MIC level against Strep. pneumoniae and help to explain the excellent clinical results reported by the studies discussed above.

A number of studies have reported on the effectiveness of oral ciprofloxacin in the treatment of bacterial infection in cystic fibrosis. ${ }^{22-2 s}$ The drug is of special interest in the treatment of patients with CF in view of its special activity against $P$. aeruginosa, Staph. aureus, and $H$. influenzae, the three pathogens that commonly cause exacerbations in these patients. The attraction lies in safety, oral bioavailability, and possible outpatient use.

Some studies show the emergence of resistance. Interestingly, this resistance does not predict clinical failure. Sometimes, patients with resistant organisms respond to therapy just as some with susceptible organisms do not. Ciprofloxacin might be useful for prolonged chemotherapy following maimum suppression of $\mathrm{P}$. aeruginosa by parenteral agents. Most authors recommend that ciprofloxacin be used intermittently in the management of the recurrent pulmonary exacerbations of bacterial infection in patients with $\mathrm{CF}$.

\section{Clinical considerations}

Since ciprofloxacin has good in vitro activity against Hemophilus, Pseudomonas, and Klebsiella, it is a good choice for bacterial exacerbations of COPD. It may be particularly useful in managing respiratory tract infections in elderly patients.

Recent studies by Peterson and colleagues ${ }^{26}$ have demonstrated the potentially useful role of oral ciprofloxacin ( $750 \mathrm{mg}$ twice a day) in the treatment of pneumonias in nursing home patients. The results with oral ciprofloxacin were comparable to the conventional parental penicillin/cephelosporin regimen. Oral ciprofloxacin has the advantage of ease of administration and cost effectiveness. Gram-negative organisms and Staphylococcus sp., which frequently cause these infections in elderly patients. ${ }^{27}$ are well covered by ciprofloxacin. The gram-negative organisms most often involved in nosocomial infections in the elderly are also highly susceptible to ciprofloxacin.

The usefulness of ciprofloxacin in treating elderly patients is enhanced by its favorable pharmacokinetics. Although age-related changes in the gastrointestinal tract may result in diminished absorption of the drug from the intestine, pharmacokinetic studies of ciprofloxacin in the elderly have shown that serum concentrations - including maximal levels - are comparable with those of younger patients. Furthermore, in some investigations, serum concentrations have been greater in elderly patients than in young control patients. Since ciprofloxacin is excreted in the urine, its clearance in elderly patients is likely to be less than that of younger patients because of age-related reductions in the glomerular filtration rate.

Ciprofloxacin may also be considered for managing respiratory tract infections in diabetic patients and alcohol abusers (except in those who with an anaerobic infection). Again, gram-negative organisms are more likely to be the cause of infection in these patients than in the general population.

\section{General recommendations}

While quinolones, such as ciprofloxacin, have been shown to be effective against Strep. pneumoniae is known to be the cause of the infection, particularly if the patient is young. In cases of mixed infections or when the pathogens are unknown, ciprofloxacin is a good choice, particularly if the patient is elderly.

For mild to moderate respiratory tract infections, the usual starting dosage of ciprofloxacin is $500 \mathrm{mg}$ 
twice daily. If the infection is judged to be more mild than moderate, one could start with $250 \mathrm{mg}$ twice daily and titrate upward as needed. For severe or complicated infections, the dosage is $750 \mathrm{mg}$ twice daily.

Ciprofloxacin is contraindicated for use in children and pregnant women. ${ }^{20}$ Oral administration of the drug has caused lameness in immature dogs. Histopathologic examination of the weight-bearing joints of the dogs revealed permanent lesions of the cartilage. Related drugs, such as nalidixic acid, cinoxacin, and norfloxacin also produce arthropathy in immature animals of various species.

Resistane to ciprofloxacin is slow to develop. Spontaneous mutants have been shown to occur only at $10^{-7}$ to $10^{-11}$ colony-forming units. Nonetheless, the drug should be used judiciously, since one may speculate that resistant strains may emerge.

Up to April 1990 intravenous ciprofloxacin has not been approved by the Federal Drug Administration (FDA). After the drug is approved, the availability of sequential intravenous/oral ciprofloxacin will make this drug an extremely attractive antimicrobial for the treatment of diverse serious infections, including those of the respiratory tract. The main advantages are convenient BID dosing, broad antimicrobial spectrum, good clinical results and anticipated cost effectiveness. $29^{-31}$

\section{Referenes}

1. Sanders CE, Sanders EW, Goering RV: Overview of preclinical studies with ciprofloxacin. Am J Med 1987;82(supp; 4A):2-11.

2. Wollschlager CM, Raoof S, Khan FA, et al.: Controlled comparative study of ciprofloxacin versus ampicillin in treatment of bacterial respiratory tract infections. Am J Med 1987; 82(suppl 4A): 164-8.

3. Wollschlager CM, Raoof S, Khan FA: Oral ciprofloxacin in the treatment of 14 patients with bacterial pneumonia. NY State J Med 1987;87:330-3.

4. Khan FA, Basir R. Sequential intravenous-oral administration of ciprofloxacin vs ceftazidime in serious bacterial respiratory tract infections. Chest, 1989;96:528-37.

5. Longworth D, Ahmad M: Initial selection of antibiotic therapy for community-acquired pneumoniae in adults JIMA 1991; 23 (in press).

6. Chaudhary BA: Establishing the etiologic diagnosis of pneumonia JIMA 1991; 23 (in press).

7. Saito A, Koga H, Shigeno H: The antimicrobial activity of ciprofloxacin against Legionella species and the treatment of experimental Legionella pneumonia in guinea pigs. J Antimicrob Chemother 1986; 18:251-60.

8. Bergogne-Berezin E, Berthelot G, Even P, et al.;
Penetration of ciprofloxacin into bronchial secretions Eur J Clin Microbiol 1986; 5:197-200.

9. Bergogne-Berezin E: Penetration of ciprofloxacin into tissue: A review, in Neu HC, Weuta $\mathrm{H}$ (eds): Proceedings of the First International Ciprofloxacin Workshop. Amsterdam, Excerpta Medica, 1985, pp 183-8.

10. Reid TMS, Gould IM, Golden D et al.: Respiratory Tract Penetration of Ciprofloxacin. Am J Med 1989; 87 (Suppl 5A):60-1.

11. Marlin GE, Brande PD, Whelan AJ, et al. ; Penetration of enoxacin into human bronchial mucosa. Am Rev Respir Dis 1986; 134:1208-12.

12 Wijnands WJA, van Herwaarden CLA, Vree TB. Enoxacin raises plasma theophylline concentrations. Lancet 1984; 2:108-9.

13. Raoof S, Wollschlager C, Khan FA: Ciprofloxacin increases serum levels of theophylline. Am J Med 1987; 82(suppl 4A):115-8.

14. Polk RE. Drug-Drug Interactions with ciprofloxacin and other fluoroquinolones. Am J Med 1989; 87(Suppl 5A): 76-81.

15. Gleadhill IC, Ferguson WP, Lowry RC. Efficacy and safety of ciprofloxacin in patients with respiratory tract infections in comparison with amoxicillin. J Antimicrob Chemother 1986;18(suppl D):133-8.

16. Kobayashi H. Clinical efficacy of ciprofloxacin in the treatment of patients with respiratory tract infections in Japan. Am J Med 1987;82(suppl 4A):169-73.

17. Davies BI, Maesen FP, Baur C: Ciprofloxacin in the treatment of acute exacerbations of chronic bronchitis. Eur J Clin Microbiol 1986; 5:226-31.

18. Ernst JA, Sy ER, Colon LH, et al.: Ciprofloxacin in the treatment of pneumonia. Antimicrob Agents Chemother 1986;29:1088-9.

19. Fass RJ: Efficacy and safety of oral ciprofloxacin in the treatment of serious respiratory infections. Am J Med 1987;82(suppl 4A):202-7.

20. Esposito S, Galante D, Bianchi W, et al. Efficacy and safety of oral ciprofloxacin in the treatment of respiratory tract infections associated with chronic hepatitis. Am J Med 1987;82(suppl 4A):211-4.

21. Chrysanthopoulos CJ, Skoutelis AT, Starakis $\mathrm{JC}$, et al. Use of intravenous ciprofloxacin in the respiratory tract infections and biliary sepsis. Am J Med 1987;82(suppl 4A):357-9.

22. Scully BE, Nakatomi $M$, Ores $C$, et al.: Ciprofloxacin therapy in cystic fibrosis. Am J Med 1987;82(suppl 4A):196-201.

23. Goldfarb J, Stern R, Reed M, et al.: Ciprofloxacin monotherapy for acute pulmonry exacerbations of cystic fibrosis. Am J Med 1987;82(suppl 4A): 174-9.

24. Bosso JA, Black PG, Matsen JM: Ciprofloxacin versus tobramycin plus azlocillin in pulmonary 
exacerbations in adult patients with cystic fibrosis. Am J Med 1987;82(suppl 4A):180-4.

25. Rubio TT: Ciprofloxacin: Comparative data in cystic fibrosis. Am J Med 1987;82(suppl 4A): 185-8.

26. Peterson PK, Stein D, Guary DRP, et al.: Prospective study of lower respiratory tract infections in an extended-care nursing home program: Potential role of oral ciprofloxacin. Am J Med 1988;85:164-1.

27. Raju L, Khan F: Pneumonia in the elderly: A review. Geriatrics 1988;43:51-62.

28. Schluter G: Toxicology of ciprofloxacin, in Neu
HC, Weuta H (eds): Proceedings of the First International Ciprofloxacin Workshop. Amsterdam, Excerpta Medica, 1985, pp 61-7.

29. Khan F. What role for quinolone in respiratory infecitons. Jour Resp Dis 1990; 11(1):31-47.

30. Rolston KV, Haron E, Cunningham C, Bodey GP: Intravenous ciprofloxacin for infections in cancer patients. Am J Med 1989; 87(Suppl 5A): 261-5.

31. Brown AE, Smith G: Treatment of sepsis in patients with neoplastic diseases with intravenous ciprofloxacin. Am J Med 1989; 87(Suppl 5A):266-8. 